University of South Florida

DIGITAL COMMONS

Digital Commons @ University of

@ UNIVERSITY OF SOUTH FLORIDA

South Florida

Academic Services Faculty and Staff

Publications

Tampa Library

Winter 12-20-2011

\title{
The Ohio Library and Information Network: Resource Sharing at Its Best!
}

Anita Cook

OhioLink, anita@ohiolink.edu

Dennis J. Smith

University of South Florida, dennissmithfl66@gmail.com

Follow this and additional works at: https://digitalcommons.usf.edu/tlas_pub

Part of the Library and Information Science Commons

\section{Recommended Citation}

Anita Cook \& Dennis J. Smith (2011): The Ohio Library and Information Network: Resource Sharing at Its Best, Journal of Interlibrary Loan, Document Delivery \& Electronic Reserve, 21:5, 219-225

This Article is brought to you for free and open access by the Tampa Library at Digital Commons @ University of South Florida. It has been accepted for inclusion in Academic Services Faculty and Staff Publications by an authorized administrator of Digital Commons @ University of South Florida. For more information, please contact digitalcommons@usf.edu. 


\section{The Ohio Library and Information Network Resource Sharing at Its Best!}

This is a preprint of an article submitted for consideration in the Journal of Interlibrary Loan, Document Delivery \& Electronic Reserve@ 2011[copyright Taylor \& Francis]; Journal of Interlibrary Loan, Document delivery \& Electronic Reserve is available online at: www.tandfonline.com http://www.tandfonline.com/doi/abs/10.1080/1072303X.2011.620442

Anita Cook \& Dennis J. Smith (2011): The Ohio Library and Information Network: Resource Sharing at Its Best, Journal of Interlibrary Loan, Document Delivery \& Electronic Reserve, 21:5, 219-225 


\begin{abstract}
The article describes the development and implementation of the Ohio Library and Information Network (OhioLINK) shared catalog and patron-initiated online borrowing process. Procedures for providing materials to patrons along with OhioLINK's experience with missing and lost materials are detailed, including lessons learned regarding lost materials and billing. Details of the usage of OhioLINK services and the growth into electronic resources are included. The article summarizes the success of this unmediated borrowing process.
\end{abstract}


The Ohio Library and Information Network (OhioLINK), a cooperative venture of university libraries and the Ohio Board of Regents, is a statewide resource sharing system (Brannan, 2010) that includes 89 Ohio college and university libraries and the State Library of Ohio (http://www.ohiolink.edu/about/what-is-ol.html). OhioLINK was established in November 1992 with the creation of a shared Central Catalog among six public universities in the State of Ohio, using software developed by Innovative Interfaces, Inc. (III). Each university utilized the III comprehensive integrated library system (ILS) and loaded their catalog records into the Central Catalog using III software that later became known as INN-Reach, for the purpose of resource sharing.

The record loading and matching process is as follows. As records from each local catalog are loaded to the Central Catalog, they are de-duplicated using a sophisticated matching algorithm (Spernoga, 2009). When two or more records match, the algorithm designates one of the records as the master record. This selection is based on two criteria: the encoding level, which indicates the fullness of the bibliographic record, and the institutional priority of the contributing library. When two matching records are found, the record that falls into the higher encoding group takes priority and becomes the master record. Assignment of the encoding group is based on a record's encoding level. Group 10 is the top priority and is reserved for Encoding Level "blank" which indicates full level cataloging from a national library. Group 2 is the lowest and contains such Encoding Levels as $U$ (unknown) and Z (not applicable). These records are the least likely to become master records. If matching records have the same encoding group, the matching algorithm looks at the institutional priority to determine which library's record becomes the master record. The top priority is Priority 1 , which includes libraries that maintain authority control over both Library of Congress (LC) Subject Headings and Medical Subject Headings (MeSH). In order to keep as many access points as possible and to serve the many medical libraries in OhioLINK, records with both LC and MeSH headings are preferred over those with only LC headings. The libraries in the Priority 2 group use OCLC for ongoing cataloging and the OCLC number is 
the preferred matching point. Priority 3 is reserved for Center for Research Libraries (CRL) records. Priority 4 is for libraries that do not use OCLC to catalog and thus lack OCLC numbers. If the institutional priority matches for the two bibs, then the first record to be loaded remains the master record.

Once a master record is chosen, holdings from all other matched records are attached to the master record. The goal is to have only one master record in the Central Catalog with all holdings attached.

\section{$\underline{\text { RESOURCE SHARING INITIATED }}$}

Patron-initiated online borrowing went live in January 1994 with 10 libraries participating. To borrow materials, patrons search in the Central Catalog, find items of interest, select the Request This Item button, and select their home institution from an alphabetic list. After the patron enters name and local ID to authenticate, the request is processed and the item is sent to the chosen pickup location. Initially, pickup locations could only be chosen from a list of local campus locations such as Main Library, Health Sciences, and Music Library. Now, after an enhancement process called "Pickup Anywhere," the user can choose a pickup location at any institution in the state.

Ten new libraries were also added to the system in 1994, and the Blackwell North America (BNA) tables of contents (TOC) were attached to the Downloaded by [University of South Florida] at 08:45 12 December 2011 Ohio Library and Information Network 221 matching bibliographic records in the Central Catalog. III wrote special programming to display this information on the first screen of the bibliographic record. The titles and authors of each TOC are indexed, which gives the patrons better access to each bibliographic record.

By 1999, the Central Catalog included Ohio's 17 public research universities, 23 community colleges, the State Library of Ohio, and 36 independent colleges, with a state-wide collection that included more than 7.3 million unique bibliographic records. Online borrowing through the OhioLINK 
Central Catalog opened doors for Ohio's undergraduate students. During a 2002 LibQual+TM study, OhioLINK received consistently higher scores on "personal control" and "access to information," which indicates the positive effect it had on library services (Gatten, 2004). Traditionally, undergraduates rarely used interlibrary loan (ILL), but by 1999, OhioLINK's easy-to-use system saw increased numbers of undergraduate borrowers and expanded service for faculty and staff needs (Sanville, 2007).

Working toward equal borrowing and lending rates, the OhioLINK program does not "raid" university collections. Instead, it works to enrich all its affiliated libraries by enabling quick and easy borrowing and lending among the college and university communities. It does this through the use of a priority table, where each institution is assigned one of three priorities (low, medium, high) based on its borrowing to lending ratio. If a library borrows more than it lends over the previous six months (priorities are adjusted every six months), then its priority will change to medium or high. If the library lends more than it borrows during the last six months, then its priority will change to medium or low. The higher a library's priority, the more likely it is to be chosen as the supplier of a request. OhioLINK experimented with only two priorities (low and high) for a number of years, but some libraries tended to swing dramatically from low to high, so a third priority (medium) was added. This has proven to be successful. By 2010, OhioLINK had added 13 additional private colleges (for a total of 49 private colleges and universities) and had over 12 million unique bibliographic records from a total of 92 institutions including one high school library and two public libraries. OhioLINK has the goal of expanding resource sharing across the state to as many citizens as possible through the further addition of public and school libraries. By 2010, we had added 13 additional private colleges (for a total of 49 private colleges and universities) and have over 12 million unique bibliographic records representing a total of 92 institutions including one high school and two public libraries. OhioLINK has the goal of expanding resource sharing across the state to many citizens as possible through the further addition of public and school libraries. 
In fiscal 2010, over 800,000 requests were handled by the 92 institutions. Figure 1 shows the number of requests per year from the beginning through calendar year 2009. Requests are initiated by the patron and the Central Catalog routes the request to the lending library where paging slips are

printed daily. Books are pulled from the shelves, checked out to the patron's library, enclosed in a bubble mailer, and placed inside a canvas mail bag labeled with the delivery location. The canvas bags are transported by statewide courier service and delivered within 48 hours. Upon receipt, materials are checked in and placed on a hold shelf. Materials are checked out using the same circulation procedures used for local items that circulate. When the patron returns the item, it is checked in using regular circulation routines. The staff person receives a notice that the item belongs to another library so it can be set aside for return. It is then repackaged, picked up by the courier service and delivered back to the book's home library, where it is checked in once more and returned to the shelf. All procedures are fully automated and the book is tracked at each status change so the system always knows where the book is in the process.

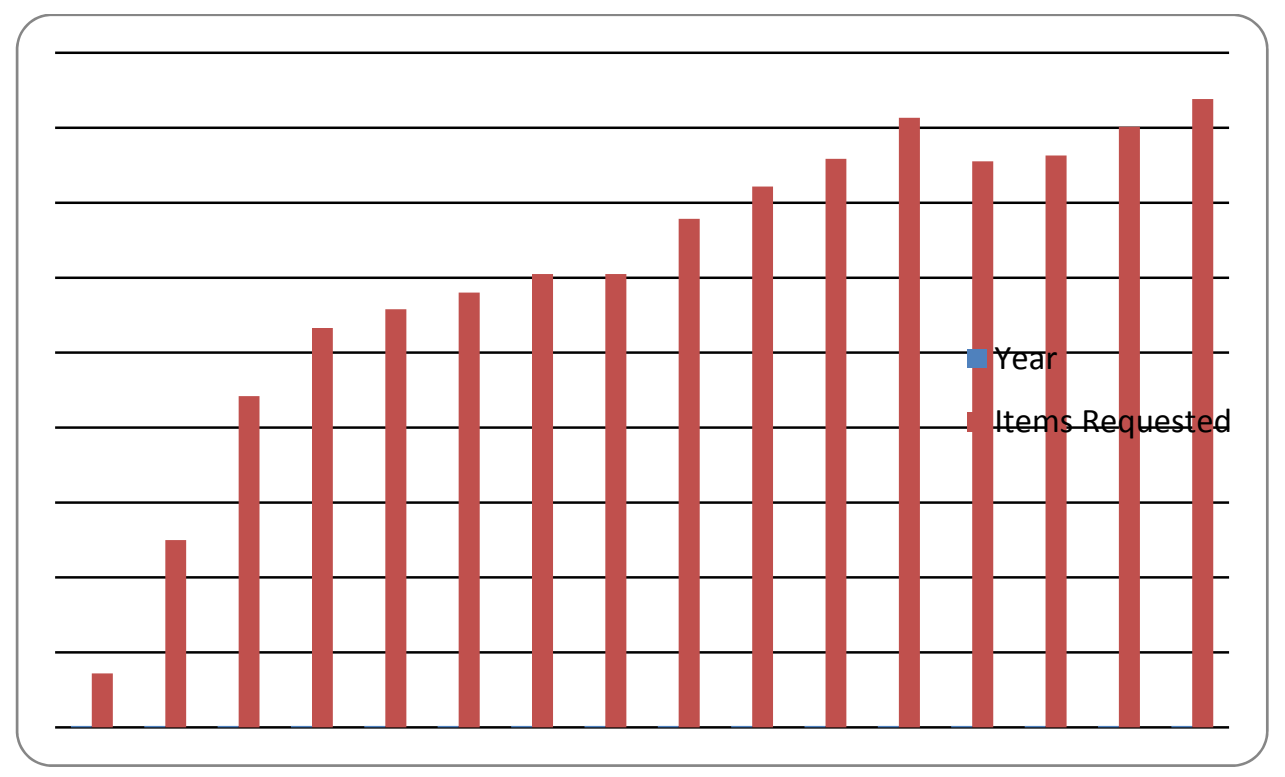

Chart One: OhioLINK Number of Annual Requests by Calendar Year 
Based on the success of patron-initiated online borrowing, OhioLINK developed services to provide access to materials other than books. The OhioLINK Digital Media Center (DMC) was developed to create a digital object repository and to facilitate the standardized collection of metadata for the online catalog, allowing swift access to and delivery of shared electronic resources (Hicks, Perkins, \& Maurer, 2007). OhioLINK Linking Service (OLinks) was also developed to provide access to full text sources, including those from licensed databases, and other digital materials (Cook \& Dowling,

2003).

\section{LESSONS, TIPS, AND TRICKS WE LEARNED ALONG THE WAY}

Given our many years of resource sharing experience, we have learned some valuable lessons and can share some helpful tips and tricks. One lesson has to do with the processing and billing of lost materials. After years of faithfully processing lost materials on an annual basis, which entailed exchanging lists, invoicing, and paying for lost materials among the different institutions, we concluded that it was far easier and more cost-effective not to do this. Instead we now process lost and long overdue items once a year, but no money exchanges hands. Rather than billing each other, the owning institution just declares the material lost and handles it locally without expecting to be reimbursed by the patron's institution. We call this the "cost of doing business." Since the percentage of lost material is less than $1 \%$ of the total number of requests, this cost is fairly low. The cost saving to the individual institutions, however, including time saved by not processing invoices and payments, is significant.

Before materials are processed as lost, patrons receive a minimum of one overdue notice one day after the item is overdue, with a billing notice sent 30 days after the due date. There is a grace period of seven days before any fines are charged. OhioLINK has very elaborate procedures for handling long overdue books and annual clean-up among institutions (InterCampus Services Committee, 2009). During the first two weeks of December, each institution runs reports for items overdue 60 days or 
more. They doublecheck their shelves to see if any items were shelved without being checked in. If these items are not found, the institution sends a report to the patron's library, where the shelves are checked in case materials were accidentally shelved. If items are still not found, the book is marked as long overdue and left active on the patron's record.

Following the same procedure, an "Institutional Overdues Annual Cleanup" is performed once a year, in the first two weeks of June. Each institution runs an institutional overdue report for items that are 700 or more days overdue. These are considered unlikely to be returned and are declared missing. Sometimes an item is discovered and can be cleared from the overdue list, but if not, the item is declared missing by the book's home library. The borrowing patron and institution are noted in the item record, and a note is also left on the patron's record at the patron's home library, in case it is returned.

Another process that was developed to streamline operations for libraries that had to pack thousands of courier bags each year was to build an automated label making system (Tang, 2000). The pull-down menus list all possible delivery locations, which allow any combination of addresses to be printed on the label (Figure 2). The label is printed and put in a clear plastic envelope fastened to the outside of the courier service's canvas mail bag. The large three-letter code in the upper right-hand corner routes the bag to one of the 12 regional sort centers around the state. The three-digit number in the upper left-hand corner is unique to that location and is used to match the paging slip to the shipping label. Since many member institutions have similar names, matching these three-digit codes instead of names has greatly reduced the number of bags going to the wrong destination. 
Figure 1: Sample of Shipping Label

то: 202

Bowling Green State Univ.

US Cargo Code:

Wm. T. Jerome Library

Ridge Street

Bowling Green, OH 43403

From: 415

Ashland University

Library

509 College Ave.

Ashland, $\mathrm{OH} 44805$

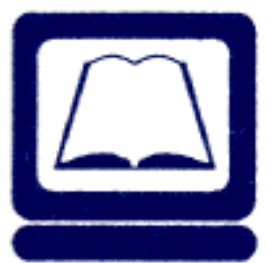

OhioLINK

To keep track of the number of bags going through the system each day (Craft, 2002), statistics are gathered on a form. This allows each pickup location in the system to track how many bags are sent to each of the other locations in the state. These totals are used to monitor the total volume of traffic annually and its rate of increase or decrease, in order to negotiate such costs as fuel surcharges or number of pickup locations with the courier each year.

\section{CONCLUSION}

OhioLINK owes its success to the dedicated and hardworking staff in each of its member libraries who work every day checking out and packing the materials that are requested by their fellow 
institutions. Even with more than 800,000 requests annually, most items are delivered to requesting patrons within two or three days. After many years of service, the network has learned quite few tricks of the trade. But OhioLINK never stops learning, and new tricks are yet to be discovered and implemented. 


\section{Works Cited}

Brannan, S. (2010). What is OhioLINK? Retrieved from http://www.ohiolink.edu/about/what-is-ol.html

Cook, A., \& Dowling, T. (2003). Linking from index to primary source: The OhioLINK model. The Journal of Academic Librarianship, 29(5), 320-326.

Craft, J. (2002). OhioLINK. Retrieved 11/14/2010, 2010, from

https://www.ohiolink.edu/ostaff/circ/manifestInstructions.html

Gatten, J. (2004). The OhioLINK LibQUAL+ 2002 experience: A consortium looks at service quality. Journal of Library Administration, 40(3/4), 19-48.

Hicks, E. A., Perkins, J., \& Maurer, M. B. (2007). Application profile development for consortial digital libraries: An OhioLINK case study. Library Resources \& Technical Services, 51(2), 116-131.

InterCampus Services Committee. (2009). OhioLINK staff information. Retrieved 11/14/2010, 2010, from https://www.ohiolink.edu/ostaff/circ/pcirc-overduesfines.html

Sanville, T. (2007). OhioLINK: A US resource sharing facility issues and developments. Interlending \& Document Supply, 35(1), 31-37.

Spernoga, M. (2009). Matching bibliographic records at the central site. Retrieved 11/14/2010, 2010, from http://platinum.ohiolink.edu/dms/DMSdocs/match.htm

Tang, H. (2000). OhioLINK mailing labels. Retrieved 11/14/2010, 2010, from http://www.ohiolink.edu/cgi-bin/uscargo.pl 